\title{
UM ESTUDO DE CASO NO MUNÍCIPIO DE MARINGÁ-PR: AS CRIANÇAS HAITIANAS E SUAS EXPERIÊNCIAS PREGRESSAS EM SEU PAIÍS DE ORIGEM
}

\author{
JuLIANE DAIANE dA SiLVA MONTANHER \\ Universidade Estadual de Maringá (UEM), Maringá, Paraná, Brasil
}

\begin{abstract}
Resumo: $\mathrm{O}$ artigo advém de um recorte de pesquisa de Mestrado que tem como questão-problema: Quais as experiências das crianças migrantes haitianas sobre suas vidas pregressas em seu país de origem? O objetivo incide em analisar os relatos de crianças migrantes haitianas sobre suas vidas pregressas em seu país de origem. Os dados foram constituídos a partir de Oficinas Lúdicas realizadas em dezenove encontros semanais envolvendo brincadeiras, jogos e roda de conversa. Os resultados revelaram que as crianças migrantes haitianas apresentam sentimentos ambivalentes em relação ao país de origem, pois disseram sentir alegria de brincar na rua do Haiti, mas apontam receio da violência vivida no país. Apresentaram nas vivências as brincadeiras de meninos e meninas (divisão por gênero) e a escola para elas está relacionada à violência física e moral. Concluímos que as experiências das crianças migrantes haitianas sobre o país natal são similares à bibliografia do Haiti como exemplo de contrastes.
\end{abstract}

Palavras-chave: Educação. Haiti. Crianças. Migrantes.

\section{INTRODUÇÃO}

Há dois anos, o Alto Comissariado das Nações Unidas para Refugiados registrou o recorde de 70,8 milhões de migrantes ao redor do mundo (ACNUR, 2019). Como resultado dos altos índices migratórios, o termo "crise migratória" passou a ser utilizado por estudiosos, jornalistas e políticos para definir o fenômeno pelo qual várias pessoas são forçadas a deixar seus países. O Brasil, no mesmo período, de acordo com o Comitê Nacional para os Refugiados, registrou 774,2 mil pedidos de residência, destacando-se as nacionalidades venezuelana, haitiana e colombiana entre os grupos de imigrantes mais recebidos pelo país (ACNUR, 2019).

O aumento das migrações no mundo está relacionado aos processos de globalização, típicos do capitalismo de acordo com vários estudos, entre eles, os de Zygmunt Bauman (2001), para quem, a fluidez deste momento da história não vem se limitando somente às tecnologias, transferências financeiras, comunicações, mas também às desterritorizações das pessoas.

A palavra migrante pode ser definida como aquele que se desloca dentro de seu próprio país ou entre países (ACNUR, 2019), que deixam suas terras por diversas razões, como guerras, desastres naturais, perseguições políticas, étnicas ou culturais (MARTINS- BORGES, 2013). Os refugiados também são considerados "migrantes", contudo, diferenciam-se dos demais, pois correm risco de morte em seus países de origem por perseguição religiosa, racial, política ou social (ACNUR, 2019). Já os apátridas 
são pessoas não titulares de nenhuma nacionalidade e nem pertencentes a nenhum Estado.

Entre os indivíduos que migram para regiões diferentes de sua origem, alguns são involuntários, são pessoas que migram por correrem risco iminente de vida, e os voluntários, são os que buscam economicamente uma vida melhor em outro lugar (BEZERRA, 2016; GARCIA, 2018). Nesse deslocamento, os migrantes muitas vezes perdem recursos materiais e culturais, mas carregam a esperança de passar a pertencer a outra nação que melhor os acolha. Apesar dessa esperança, os recém-chegados nem sempre são desejados pela nação que os recebe, pois são considerados "estranhos que tendem a causar mal-estar diferentes das pessoas que aí vivem" (BAUMAN, 2017). Por essa razão, muitas vezes, migrantes e refugiados são considerados como o "lixo da humanidade" (BAUMAN, 2001) ou os "esfarrapados" do mundo (BORGES, 2019, p. 47), convivendo com a xenofobia e o ódio por parte de diferentes grupos sociais.

Por vezes, acreditamos que o Brasil, por ser um país predominantemente miscigenado, composto por brancos, negros e indígenas, além de ter recebido grandes levas de imigrantes europeus e japoneses, entre outras nacionalidades, poderia não apresentar essas características xenofóbicas. Porém, comumente ouvimos que os estrangeiros, em especial, os "negros trabalham demais e roubam 'nossos empregos"" ou que são "folgados, verdadeiros bichos-preguiça, que se divertem e descansam à custa do duro labor dos nativos" (KOLTAl, 2009, p. 146). Por consequência, de acordo com o autor, construiu-se uma teia de clichês e estereótipos racistas, por meio da qual a sociedade brasileira tem se desviado de suas responsabilidades sociais com os migrantes.

É a partir desse contexto, portanto, que desenvolvemos nossa pesquisa, cuja apresentação inicia-se com a discussão de três conceitos basais: migrações, infância e infância migrante. $\mathrm{O}$ critério para trabalhar com o grupo de crianças deu-se mediante contato com a coordenação da Pastoral do Migrante da Paróquia Santa Rita de Cássia e com o padre responsável pela paróquia, situada em Maringá-PR. A pesquisa foi realizada com oito crianças haitianas, com idades entre três anos e dez meses e onze anos, participantes de um projeto de acolhimento de imigrantes da Paróquia Santa Rita de Cássia. Os dados produzidos pelas crianças migrantes durante as atividades realizadas nas Oficinas Lúdicas foram submetidos ao método de Análise de Conteúdo (BARDIN; 2011) a partir das experiências das crianças haitianas no seu país de origem. A categoria Experiências pré-migratórias: Haiti foi adaptada da problemática de Cecília Braga Bezerra (2016) em trabalho similar realizado com crianças haitianas, sírias e venezuelanas. A nossa categoria foi dividida em três subcategorias: Brincadeiras e jogos; Escola: uniforme, comida e disciplina; Criminalidade e morte: vagabundos e bandidos.

\section{Procedimentos DA PESQUISA}

Para a realização das Oficinas Lúdicas, buscamos selecionar brincadeiras jogos e livros de literatura infantil conforme os objetivos de nossa pesquisa e os interesses e gostos que as crianças manifestavam ao longo dos encontros com a pesquisadora. A metodologia contribui para o delineamento de pesquisa com crianças, cuja base é o 
protagonismo das ações e das vozes infantis. Por essa razão, essas atividades foram sendo selecionadas durante o próprio processo de pesquisa e, portanto, não foram previamente definidas. Organizamos os encontros seguindo a sequência de: aquecimento, desenvolvimento e encerramento. O momento de aquecimento dos encontros constituiu-se na forma de roda de conversa para a retomada dos acontecimentos do encontro anterior com as crianças, assim como para ouvir suas vivências cotidianas da semana em casa ou na escola. Reproduzindo em parte os procedimentos da pesquisa de Faeti (2017), no momento de desenvolvimento dos encontros, realizamos jogos, brincadeiras, leitura, músicas e danças. No intervalo fizemos lanches e, em seguida, no momento de encerramento, realizamos uma nova roda de conversa para debater sobre o que havíamos feito naquele encontro e para as crianças poderem compartilhar como se sentiram, do que gostaram, do não gostaram, para ouvir e propor sugestões sobre o que devíamos fazer no próximo encontro.

Para o registro dos encontros com os participantes, usamos um diário de campo e gravações de áudio de todos os encontros. Os registros escritos contribuíram com as informações gravadas, e a escolha pela gravação dos encontros se deve ao fato de poder promover um vínculo da pesquisadora com os participantes, pois, como lembra Guacira Lopes Louro (1997, p. 26), gravar permite deixar o pesquisador livre "para prestar atenção no (a) interlocutor (a) e nas circunstâncias da entrevista".

Realizamos dezenove encontros com as crianças participantes da pesquisa, nos quais foram desenvolvidas as atividades das Oficinas Lúdicas. Cada encontro teve duração de duas horas e meia, com periodicidade de uma vez por semana, durante as aulas de português de seus familiares no salão da Paróquia Santa Rita de Cássia. No primeiro encontro buscamos promover as apresentações e a socialização entre as crianças, e entre elas e a pesquisadora. Durante o momento de aquecimento, realizamos uma conversa em grupo. Após a apresentação das crianças, dizendo o seu nome, sua idade, onde estudava e suas brincadeiras prediletas, solicitamos o auxílio de Jogador ${ }^{1}$ $(11)^{2}$, uma das crianças participantes, que melhor dominava a língua portuguesa, para nos fazermos entender pelas demais crianças com maior adequação. Após este momento, passamos ao desenvolvimento do encontro, conforme esta metodologia, que seguimos em todos os encontros: aquecimento, desenvolvimento e encerramento (QUADRO 1).

Quadro 1 - Momentos e atividades das Oficinas Lúdicas.

\begin{tabular}{|c|c|c|}
\hline Momento 1 & Aquecimento & $\begin{array}{c}\text { Roda de Conversa: relato } \\
\text { de vivências cotidianas. }\end{array}$ \\
\hline Momento 2 & Desenvolvimento & $\begin{array}{c}\text { Atividades: jogos, } \\
\text { brincadeiras, letiura, } \\
\text { música, dança. }\end{array}$ \\
\hline Momento 3 & Encerramento & $\begin{array}{c}\text { Roda de conversa: síntese e } \\
\text { avaliação do encontro. }\end{array}$ \\
\hline
\end{tabular}

Fonte: Elaborado pela pesquisadora (2020).

Em acordo com esta metodologia, a cada encontro os três momentos da Oficina Lúdica desenvolveram temas relativos às vivências das crianças em seu país natal e como elas se sentiam vivendo essas experiências em seu processo de inserção no novo 
país. Temas como escola, professores e famílias foram estimulados pelas rodas de conversa e pelas atividades realizadas. As atividades eram feitas em cada encontro durante o período de desenvolvimento (Momento 2), uma vez que o aquecimento (Momento 1) e o encerramento (Momento 3) se organizaram como rodas de conversa. Reiteramos que essas atividades foram realizadas buscando atender às sugestões e interesses das crianças, manifestados por elas durante as rodas de conversa, e foram previamente organizadas pela pesquisadora antes dos encontros.

\section{MIGRAÇÕES: CONCEITOS FUNDAMENTAIS}

A palavra migrar tem origem etimológica do latim migrare (MIGRAR, 2020) que, de acordo com a coluna Migração em Debate, do site Museu da Imigração do Estado de São Paulo (2019), denota "mudar de residência/condição". De acordo com a Agência da Organização das Nações Unidas para Refugiados no Brasil - ACNUR (2019), a palavra migrante indica "aquele que se desloca dentro de seu próprio país, mas também pode ser usada para falar dos deslocamentos entre países. Os refugiados também são considerados "migrantes". Contudo, diferencia-se dos demais, pois correm risco de morte em seus países de origem, por perseguição religiosa, racial, política ou social. A instituição define também os apátridas, migrantes não titulares de nenhuma nacionalidade e nem pertencentes a nenhum Estado.

Lucienne Martins-Borges (2013) acrescenta que o significado atualmente atribuído aos migrantes está relacionado àqueles que deixam suas terras por diversas razões, como guerras, desastres naturais, perseguições políticas, étnicas ou culturais. Além disso, pesquisas utilizam o termo imigrante para indicar o indivíduo que entrou no país estrangeiro voluntariamente.

O tema migração vem sendo comentado com frequência em diversos campos de estudos, porém, conforme Helion Póvoa Neto (1997, p. 12), "não existe, pois, um corpo uniforme de estudiosos e planejadores a examinar um conjunto de fenômenos consensualmente delimitado", o que não justifica a impossibilidade de análise, "mas obrigam que sejamos menos ingênuos ao analisá-los". Por conta disso, optamos por adotar neste artigo a denominação sugerida pelo pesquisador que denomina este campo de estudos como "questão migratória" (PÓVOA NETO, 1997, p. 14).

Para esse autor, a denominação "questão migratória" parece ser a mais adequada para designar esse tipo de movimento de pessoas pelo mundo, pois envolve "um campo de enfrentamento de posições políticas e metodológicas a respeito da migração", tornando-se grande terreno de atuação do Estado que controla, incentiva, distribui e fiscaliza os migrantes no mundo todo (PÓVOA NETO, 1997, p. 12). Conforme evidencia Mirelle Amaral, de São Bernardo (2016, p. 30), a imigração faz parte da história brasileira desde sua colonização: inicialmente colonizado por europeus e pessoas escravizadas africanas que foram arrancadas de seus países e trazidas involuntariamente ao Brasil e, em seguida, recebeu imigrantes vindos dos países asiáticos, nos períodos da primeira e segunda guerra mundial, imigrações que perduraram até meados do século XX. Depois da década de 1980, iniciou-se "um processo inverso e surge então um fluxo emigratório, principalmente com destino a América do Norte, Japão e países da Europa 
Ocidental em busca de trabalho e melhores condições de vida" (BERNARDO, 2016, p. 30). Nos últimos anos, o país voltou a receber imigrantes bolivianos, venezuelanos, e "de países da América Central como o Haiti, de países africanos e até mesmo países mais distantes como Síria, Bangladesh, China, Coréia", pois, além da crise econômica internacional, esses imigrantes são atraídos pela democracia (BERNARDO, 2016, p. 31).

Como exemplo disso, é citada a crise econômica da Venezuela de 2014, na qual mais de 4 milhões de pessoas deixaram seu país, migrando para Colômbia (1,3 milhão), Peru (768 mil), Chile (288 mil), Equador (263 mil), Brasil (168 mil) e Argentina (130 mil). No Brasil, o crescimento migratório de haitianos vem ocorrendo, sobretudo depois de 2010, agravado pela ocorrência de um grande terremoto que destruiu o país. Desse modo, o Haiti constituiu-se de uma área produtora de mão de obra, em que sua população se tornou móvel para migrar, isto é, para vender a sua força de trabalho para os polos de atração (ACNUR, 2019).

Conforme a Agência Brasil (2020), na última década tem se intensificado a entrada de imigrantes venezuelanos, bolivianos e haitianos nos países mais estáveis da América do Sul por diferentes motivos, como coibição política, declínio econômico, falta de alimentos e desastres naturais. De acordo com a Folha de São Paulo, em publicação de março de 2020, a escolha desses migrantes por países da América do Sul, como o Brasil, é explicada, em parte, pelo endurecimento de sua entrada por parte de países desenvolvidos do continente, como os Estados Unidos e o Canadá. Essas informações são confirmadas por Tadeu Oliveira, coordenador do OBMigra - Observatório das Migrações Internacionais do Brasil, que afirma que vem ocorrendo uma mudança da imigração Norte-Sul (de países do Norte global para os do Sul global) para Sul-Sul (FOLHA DE SÃO PAULO, 2020).

\section{INFÂNCIA E INFÂNCIA MIGRANTE: CONCEITOS}

A infância é assunto controverso e polêmico entre os historiadores e pesquisadores do mundo ocidental (HEYWOOD, 2004; ARIÈS, 1981). É ponto comum, porém, a ideia de que a infância se constitui numa construção histórica e política relacionada diretamente às mudanças em diferentes áreas da sociedade, como a econômica, a cultural e a moral. No Brasil, o conceito de infância sofreu a influência dos migrantes europeus que chegaram durante todo o século XX ao nosso país.

Segundo Marisa Lajolo (1997, p. 225, grifo da autora), "as palavras infante, infância e demais cognatos, em sua origem latina e nas línguas daí derivadas, recobrem um campo semântico estreitamente ligado à ideia de ausência de fala". Dessa forma, cabe explicar que a "infância [vista] como qualidade ou estado do infante, isto é, d'aquele que não fala, constrói-se a partir dos prefixos radicais linguísticos que compõem a palavra: in = prefixo que indica negação; fante = particípio presente do verbo latino fari que significa falar" (LAJOLO, p. 225, grifo da autora). Para a autora, essa definição ainda é condizente no espaço social, pois enquanto a criança não for sujeito do seu discurso, essa etimologia será viável.

Para os estudiosos Adelma Pimentel e Lucivaldo da Silva Araújo (2007, p. 185), a palavra criança, proveniente "do latim creantia, criantia", tem sido alvo de estudos e sofrido modificações de acordo com diversas culturas. De acordo com o dicionário Aurélio: a criança pode ser designada como um "[...] ser humano de pouca idade, 
menina ou menino. [...]" (FERREIRA, 2010, p. 208, grifo do autor), enquanto a infância é a "[...] etapa da vida humana que vai do nascimento à puberdade; puerícia, meninice" (FERREIRA, 2010, p. 424, grifos do autor).

Ao refletirmos sobre a infância no Brasil, desde o início da colonização no século $\mathrm{XVI}$ até o século XXI, é possível analisar que, ao longo de sua história, a criança nem sempre foi acolhida e cuidada, pelo contrário, grandes contingentes de crianças foram e continuam sendo abandonados e explorados mesmo sendo legalmente cidadãos de direitos na atualidade. Nesse grupo de crianças, expostas a situações de violência física ou moral, incluem-se as crianças migrantes que chegaram ao Brasil de forma involuntária, por meio da escravidão, e as crianças que até hoje continuam chegando involuntariamente em fuga da fome, da violência e da morte.

Atualmente, conforme a Agência da ONU para Refugiados no Brasil - ACNUR, cada vez mais crianças, acompanhadas ou não de suas famílias, deslocam-se de seus países de origem fugindo da fome, dos desastres naturais e dos conflitos armados. Elas representam 52\% da população imigrante do mundo, são crianças vulneráveis a múltiplas violências (ACNUR, 2019). Segundo Grajzer (2018, p. 104-105), muitas delas imigram sem documentos, tornando-as mais suscetíveis "ao risco de tráfico humano, exploração sexual ou de trabalho infantil, e estão entre aquelas que as autoridades locais têm maior dificuldade em localizar, logo são as mais difíceis de proteger de abusos".

Fato semelhante ocorre com crianças que se deslocam junto às suas famílias entre os estados brasileiros. De acordo com Karina Strohhecker Lisa Alcubierre (2017, p. 216), crianças migrantes brasileiras vivenciam durante e após o deslocamento, situações como: violência urbana e social, conflitos familiares e pobreza extrema, essas "crianças convivem com dramas sociais que afligem o Brasil e que, por serem cada vez mais comuns e cotidianos, recaem sobre o imaginário infantil como uma normalidade". Em seus estudos, a autora aborda falas das crianças migrantes em Florianópolis que demonstram seu difícil contexto - grupo explorado e desapropriado de direitos.

Em um país marcado pela desigualdade social, as crianças migrantes são aquelas que carregam na infância marcas dessa realidade, crianças que já carregam profundas dores. Complementar a isso, Bahia e Santos $(2016$, p. 6) destacam que, além da carga emocional exaustiva, essas crianças enfrentam diariamente "medo e receio pela nova terra, dos novos colegas e do novo idioma". Os autores argumentam que no caso das crianças e dos adolescentes que já têm o conhecimento da leitura e da escrita, cabe ao professor objetivar a aprendizagem, de modo "que a criança compreenda a língua portuguesa, e não a torne apenas uma copista em sala de aula, que aparentemente lê e escreve na língua portuguesa, porém não age, não compreende nem utiliza o que reproduz na escola em seu cotidiano" (BAHIA E SANTOS, 2016, p. 8).

Além disso, a pesquisa de Rodrigues et al. $(2014$, p. 15) considera que as crianças imigrantes não recebem da escola a devida valorização de suas histórias e culturas, "isto indica que os profissionais da educação atuantes nas escolas desconhecem o significado da imigração e as implicações disso nos sujeitos imigrantes". Ademais, há professores que pedem à família das crianças que evitem o idioma materno em casa, segundo os autores, o professor "parece desconsiderar a importância da manutenção da cultura como forma de estabilizar a identidade e dar significado à mudança" (RODRIGUES et al., 
MONTANHER, J. D. da S

2014, p. 15). Dessa forma, é necessário ampliar aos profissionais da educação, principalmente aos que lidam com crianças imigrantes, o entendimento da imigração, suas funções e consequências.

\section{EXPERIÊNCIAS PRÉ-MIGRATÓRIAS: HAITI}

Dessa categoria fazem parte os relatos das crianças sobre situações vividas em seu país de origem, representado como um lugar de liberdade e de muita brincadeira nas ruas, mas também, simultaneamente, como um lugar perigoso de muitos "vagabundos, desordem social e violência". O que nos leva a supor que as crianças têm sentimentos ambivalentes sobre seu país de origem, hipótese confirmada em seus depoimentos sobre suas vivências na escola, nas ruas, nas brincadeiras.

Os dados produzidos pelas crianças e organizados na subcategoria, brincadeiras e jogos, sugerem experiências dessas atividades fortemente relacionadas ao gênero de quem brinca e joga. O diálogo entre a pesquisadora e os dois meninos, Goleiro (07) e Jogador (11), reforçam essa hipótese quando o primeiro solicita massinha rosa para brincar e o segundo o repreende dizendo: "Você não é menina".

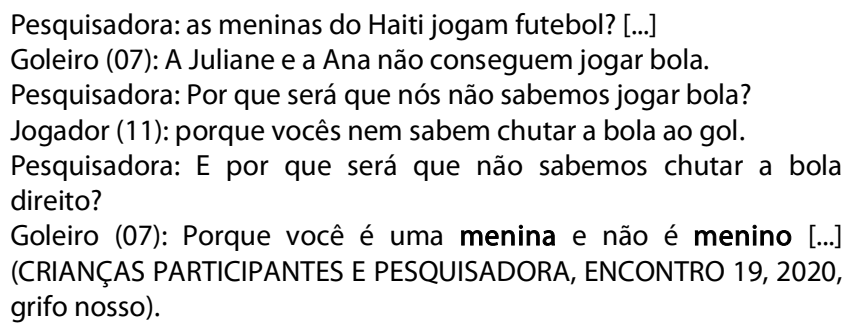

Em outra situação Jogador (11) se nega a participar da atividade com massinha de modelar e ao ser perguntado se já tinha brincado alguma vez, respondeu: "não, jamais" e que gostaria de "jogar bola". (JOGADOR, ENCONTRO 03, 2020). Ao contrário dos outros meninos participantes da pesquisa que sempre solicitavam brincar com massinha, o Jogador (11) se recusou, sugerindo que por aqueles serem mais novos, suas visões de masculinidade seriam menos cristalizadas. Essas vivências de brincadeiras e jogos diretamente vinculadas ao gênero foram encontradas também em outro momento do grupo quando o Jogador (11) comenta que "no Haiti as meninas só ficam brincando com bonecas" (JOGADOR, ENCONTRO 18).

Esses resultados reforçam os encontrados na pesquisa de Adriano Alves de Aquino Araújo (2015), que também constatou a desigualdade de gênero na cultura haitiana. Segundo o autor, as primeiras diferenças já surgem na infância quando é priorizada a educação formal aos meninos, uma vez que no Haiti a educação é paga, dificultando a inserção de todas as crianças, principalmente das meninas. Neste país a vida das meninas e das mulheres é penosa, além da educação, "o Estado não garante o acesso à saúde e métodos contraceptivos, culminando em altas taxas de natalidade aliada a altas taxas de mortalidade materna" e, não raro, elas suportam violência sexual, física e psicológica, muitas são obrigadas trabalhar formalmente e no lar, cuidando não só dos filhos e marido, em alguns casos, de cunhado, primo, tio. (ARAÚJO, 2015, p. 23). 
De acordo com Renel Prospere (2017, p. 104), essas condições desiguais, entre meninos e meninas, se deve à decadência da educação pública que leva os pais a escolherem os filhos em detrimento das filhas para estudar e se qualificar profissionalmente. Desse modo, "perto de um milhão de crianças não podem frequentar a escola, às vezes, é porque os estabelecimentos não existem ou, às vezes, são muito afastados de suas residências, ou ainda porque os custos da escola são demasiado elevados".

Durante os encontros com a pesquisadora, as crianças mostraram algumas brincadeiras de rua que costumavam brincar em seu país natal, demonstrando alegria e satisfação. Essas manifestações de afeto nos remetem às conclusões de Bezzera (2016, p. 111), para quem: as brincadeiras são essenciais para o não adoecimento das crianças migrantes, pois "favorece o desenvolvimento emocional da criança, aproxima-lhe das experiências vividas no país de origem e a protege do contato com mais uma ruptura". Nas falas a seguir, procuramos evidenciar a espontaneidade e o prazer das crianças participantes em ensinar em uma de suas brincadeiras nativas ${ }^{3}$.

Pesquisadora: Qual o nome dessa brincadeira? Jogador (11): Não sei.

Goleiro (07): Não lembro. Massinha (03): Sei não.

Pesquisadora: Hum, beleza. Se vocês lembrarem me falam, por favor. Pesquisadora: Como brinca? Podem por gentileza me ensinar?

Jogador (11): Sim prô. É assim. Você tem que andar aqui. Pesquisadora: Aqui nos triângulos?

Jogador (11): Sim. Mas somente com um pé e tem que empurrar a pedra ou um chinelo sem pisar nas linhas. Aí, ganha quem passar por todos números. (conforme modelo abaixo)

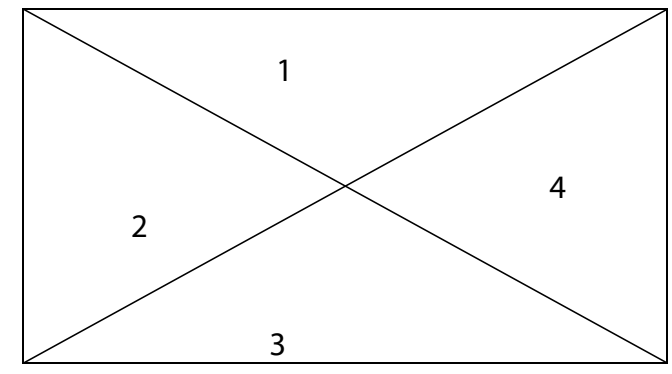

Pesquisadora: Vocês já tinham brincado aqui no Brasil? Goleiro (07): Não, é a primeira vez.

Pesquisadora: Lá no Haiti vocês brincavam em qual local? Goleiro (07): Na rua. (ENCONTRO 19).

Nesses momentos expressões corporais, faciais e gestuais das crianças sugeriram que brincar essas brincadeiras de sua terra natal lhes serviam de momentos 
MONTANHER, J. D. da S

de rememoração e reencontro com seu passado. Em outro encontro, as crianças brincaram com pedrinhas que ainda não haviam brincado em nosso país.

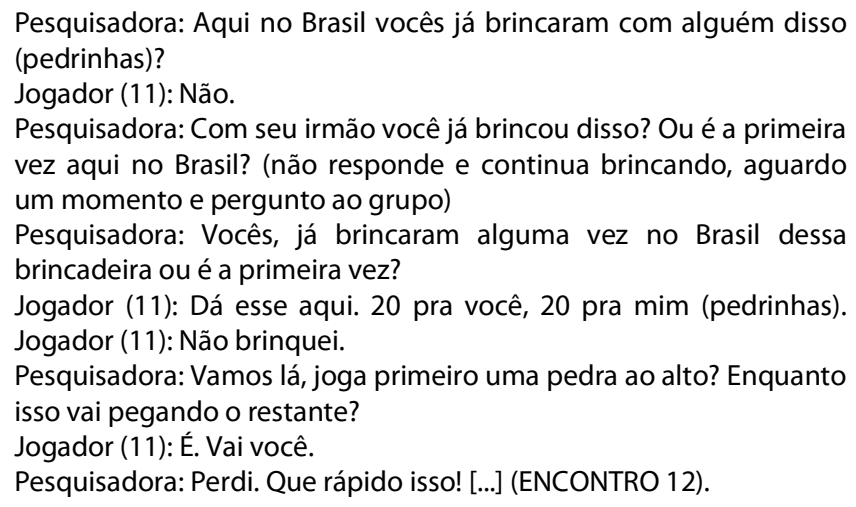

Além das brincadeiras, durante os encontros com a pesquisadora as crianças apresentavam seus relatos sobre suas vivências em seu país de origem que incluímos na subcategoria Escola: uniforme, comida e disciplina. Em um dos encontros, Jogador (11) imita uma professora haitiana repreendendo e batendo em um estudante e Batman (06) começa a reproduzir os gestos de seu colega. Massinha (03) e Jogador (11) começaram rir da situação e Jogador (11) comentou que no Haiti "todos professores batem nos alunos".

Jogador (11): No Haiti todos os professores batem nos alunos. Pesquisadora: Em você ela já bateu? Jogador (11): Já. Já. [...]

Jogador (11): Se tiver dois alunos conversando, ela chama os dois e faz assim ó ó. (Pega a régua e bate em suas mãos). [...] Jogador (11): Assim ó, muito forte ano. Eu tô chorando. (ENCONTRO $08)$.

Neste encontro, Jogador (11) ainda relata que a professora "batia nos alunos e briga com eles" manifestando seu descontentamento com o tratamento recebido.

Jogador (11): Eu ficava muito bravo quando minha professora do Haiti me batia, não achava isso certo.

Jogador (11): Eu ficava bravo. (ENCONTRO 10).

As crianças haitianas apresentaram várias lembranças desagradáveis e tristes sobre suas experiências na escola. Outro participante, Goleiro (07), também relata: “Eu não gosto escola do Haiti. A professora batia e eu chorava [...] ela pegava um galho da árvore e batia. [...] Eu não merecia porque eu não tinha feito nada". (ENCONTRO 10). De acordo com seu relato, as professoras usavam régua, galhos de árvore ou bastões para discipliná-los e repreendê-los quando se comportavam fora das normas estabelecidas pela escola. 


\begin{abstract}
Goleiro (07): "A professora Haiti me bate! [...] ! Cor de Rosa (07): A gente fazia bagunça!

Jogador (11): Ela pegava um bastão assim" (ele faz som do bastão). Noiva (07) A professora estava andando e viu eu jogando a água no chão, aí ela falou que iria me pegar". (ENCONTRO 17).
\end{abstract}

Como podemos supor pelos relatos das crianças, a realidade escolar haitiana se mostrou violenta, física e moralmente. Se levarmos em conta a realidade violenta da sociedade haitiana, cujos índices de mortes e miséria continuam sendo muito graves, a escola seria um reflexo dela. Ainda hoje o país padece com a instabilidade política; o atual presidente Jovenel Moise foi acusado de corrupção, levando milhares de manifestantes às ruas. A pobreza extrema do país, por conta da escassez de alimentos e combustíveis, a inflação perto dos $20 \%$ ao ano e os surtos de doenças, como difteria, tétano e coqueluche (FOLHA DE SÃO PAULO, 2019), revelam uma tragédia social e pessoal, obrigando vários indivíduos a deixarem sua terra natal em busca do direito de uma vida minimamente digna em outro local.

Podemos aventar a hipótese de que a violência escolar possa estar reproduzindo essa situação em seu microcosmo. Como nos lembra Paulo Freire $(1975, \mathrm{p}$. 30), "não é a educação que forma a sociedade de uma determinada maneira, senão que esta, tendo-se formado a si mesma de uma certa forma, estabelece a educação que está de acordo com os valores que guiam essa sociedade". Em outras palavras, a escola não está isolada da sociedade, pelo contrário, as duas estão intrinsecamente relacionadas.

Ao passar por situações como desastres naturais, econômicos e políticos, o Haiti continua vivendo altos índices de violência e criminalidade lembradas e relatadas pelas crianças participantes da pesquisa que incluímos em uma subcategoria denominada Criminalidade e morte: vagabundos e bandidos. Em um dos encontros do grupo, as crianças comentam manifestando receio sobre bandidos, criminosos e mortes dos quais sua família e amigos falaram:

Goleiro (07): Eu não gosto do Haiti, lá tem criminosos. [...] Jogador (11): Sim, tem um bandido que chama Anel que tem 'muito' arma. [...]

Goleiro (07): Ele mata muita gente.

Jogador (11): Ele briga com polícia também. [...]

Noiva (07): Tenho (saudade), mas é muito chato. Eu não gosto de ficar no Haiti, porque chegou bandido para matar e destruir a cidade. $\mathrm{E}$ as policias foram morrendo e as pessoas foram morrendo. (ENCONTRO 05).

Embora não tenham contado se estiveram envolvidas diretamente em situações deste tipo, os relatos das crianças e seu temor em viver no Haiti por conta da violência evidenciam a relevância deste fator para suas visões negativas sobre seu país de origem. Isso é reforçado pelo conhecimento das crianças sobre o envolvimento de familiares em situações de violência, seja como criminosos ou policiais, segundo Jogador (11): "Primo que é muito vagabundo" [...] "Se ele vem aqui no Brasil briga com todo mundo, no Haiti também briga com todo mundo [...] (ENCONTRO 05). No encontro 
MONTANHER, J. D. da S

dezessete, Noiva (07) aborda novamente os problemas sociais do país natal, "Eu não gosto muito do Haiti, tem muita doença, muita gente matando as pessoas, os polícias" (ENCONTRO 17).

\section{CONSIDERAÇÕES FINAIS}

De acordo com Vagner Charles (2015, p. 82), em 2001 foi criado no Haiti um projeto de lei que coibia agressões físicas a crianças na escola e em casa. No entanto, de acordo com o autor, quatorze anos após a provação do projeto ainda "[...] é comum ocorrer violências físicas no ambiente escolar, uma vez que não há fiscalização e nem punição aos professores que cometem as agressões" e dependendo da família do aluno, é preferível que o professor castigue o aluno fisicamente. Conforme sua constatação, os pais haitianos batem em suas crianças "mais do que os professores para provar a sua severidade, [uma vez] que não toleram o menor erro". Segundo dados de pesquisa do Parlamento Europeu (2018, p. 2), no Haiti cerca de "85\% das crianças entre os 2 e os 14 anos são vítimas de atos de disciplina violenta em casa, $79 \%$ são vítimas de castigos corporais e $16 \%$ sofrem de castigos corporais extremos".

Ao finalizarmos o presente artigo, concluímos que os relatos das crianças migrantes haitianas sobre o país natal são similares à bibliografia do Haiti como exemplo de contrastes, povo sofrido, povo risonho. Da natureza exuberante ao lixo a céu aberto, de governo instável e de população resiliente, de deterioração econômica, problemas climáticos, sociais e políticos. Tudo isso no mesmo país.

Os relatos das crianças haitianas e de seus familiares participantes de nossa pesquisa são convergentes com os encontrados por Giroto (2020), que diz que a saída dos hatianos de seu país está relacionada à dificuldades de acesso e permanência das crianças e adolescentes no sistema educativo. Como conclui o pesquisador (2020, p. 125), os migrantes "descrevem o ensino no Haiti como rígido, enquanto no Brasil apresenta-se de forma mais flexível", uma vez que no país de origem o conteúdo teria que ser decorado, caso não fosse, haveria agressões físicas e verbais dos professores.

Sobre o Haiti, eles relembraram sua alegria de brincar na rua, mas apresentaram relatos de violência vivida no país. Dizem sentir saudade de amigos e parentes, mas querem esquecer as doenças e a falta de água de seu país. Também apresentaram suas visões das brincadeiras de meninos e de meninas, diferenciando-as de acordo com o gênero, e a escola está relacionada à violência física e moral.

Artigo recebido em: 02/04/2021 Aprovado para publicação em: 28/05/2021

\section{A CASE STUDY IN THE CITY OF MARINGÁ-PR: HAITIAN CHILDREN AND THEIR EARLY EXPERIENCES IN THEIR COUNTRY OF ORIGIN}

ABSTRACT: The article has origin in a Master's research that has the following problem: What are the experiences of Haitian migrant children about their past lives in your home country? The 
objective focuses on analyzing the reports of Haitian migrant children about their past lives in their country of origin. The data were constituted from Playful Workshops held in nineteen weekly meetings involving games, games and conversation circles. The results revealed that Haitian migrant children have ambivalent feelings towards the country of origin, they presented that they feel the joy of playing on the street in Haiti, but they pointed to the fear of the violence experienced in the country, and they showed experiences of the games played by boys and girls and the school related to physical and moral violence. We conclude that the experiences of Haitian migrant children about their home country are similar to the Haitian bibliography as an example of contrasts.

KEYWORDS: Education. Haiti. Children. Migrants.

\section{UN ESTUDIO DE CASO EN LA CIUDAD DE MARINGÁ-PR: LOS NIÑOS HAITIANOS Y SUS PRINCIPIAS EXPERIENCIAS EN SU PAÍS DE ORIGEN}

RESUMEN: El artículo es el resultado de un extracto de la investigación del Magister que tiene como planteamento del problema: Cuáles son las experiencias de los niños haitianos migrantes en relación a sus vidas recién pasadas en su país de origen? El objetivo radica en analizar los informes de los niños haitianos migrantes y sus vidas recién pasadas en su país de origen. Los datos fueron construídos a partir de los Talleres Lúdicos (Oficinas Lúdicas) llevados a cabo en diecinueve encuentros semanales con actividades, juegos y ruedas de conversaciones. Los resultados mostraron que los niños haitianos migrantes presentaron sentimientos ambivalentes relacionados con su país de origen, afirmaron sentir alegría en poder jugar en las calles de Haití pero señalizaron el temor de la violencia que vivieron en el país, mostraron experiencias de los juegos de niños y niñas y la escuela está relacionada con la violencia física y moral. Pudimos concluir que las experiencias de los niños haitianos migrantes sobre su país natal son parecidas a las de la bibliografia de Haití, como un ejemplo de contrastes.

PALABRAS CLAVES: Educación. Haití. Niños. Migrantes.

\section{NOTAS}

1 - As crianças participantes da pesquisa receberam nomes fictícios que foram escolhidos por elas no decorrer das Oficinas Lúdicas.

2 - Idade das crianças participantes da pesquisa.

3 - Pareceu-nos semelhante ao jogo conhecido por nós como jogo da Amarelinha: https://www.cleanipedia.com/br/familia/amarelinha-historia-como-brincar.html.

4 - Pareceu-nos semelhante ao jogo conhecido por nós como o jogo Três Marias: variadas.cnfcp.gov.br/tesauro/0001196.htm\#: :text=Busca\%20na\%20Internet-, Três- marias, jogo\%2C\%20que\%20apresenta\%20jogadas\%20variadas. 
MONTANHER, J. D. da S

\section{REFERÊNCIAS}

ACNUR. Migrações, Refugiados e Apatridia. Guia para comunicadores. 1. ed. Brasília: FICAS, 2019. E-book. Disponível em: $<$ https://www.acnur.org/portugues/wpcontent/uploads/2019/05/Migracoes-FICAS\%20color_FINAL.pdf >. Acesso em: 06 out. 2019.

ALCUBIERRE, K. S. L. Crianças migrantes: sentidos e memórias da objetividade vivida. FLORIANÓPOLIS, 2017.

ALEXANDRE, Ivone Jesus. A presença das crianças migrantes haitianas nas escolas de Sinop/MT: o que elas visibilizam da escola? 2019. Disponível em: $<$ https://repositorio.ufscar.br/bitstream/handle/ufscar/11681/tese-

\%20ivone\%20jesus\%20alexandre-alterada.pdf?sequence $=4 \&$ isAllowed $=\mathrm{y}>$. Acesso em: 10 jan. 2021.

ARAÚJO, A. A. A. Reve de Brezil: A inserção de um grupo de imigrantes haitianos em Santo André, São Paulo - Brasil. Santo André: Dissertação de Mestrado. Programa de PósGraduação em Ciências Humanas e Sociais - UFABC, 2015. 2020.

ARIÈS, P. História social da criança e da Família. Tradução: Dora Flaksman. 2ed. Rio de Janeiro: LTC, 1981.

BAHIA, J; SANTOS, M. (org.). Um olhar sobre as diferenças: a interface entre projetos educativos e migratórios. São Paulo: Oikos, 2016.

BAUMAN, Z. Estranhos à nossa porta. Tradução: Carlos Alberto Medeiros. 1. ed. Rio de Janeiro: Zahar, 2017. Modernidade Líquida. Tradução: Plínio Dentzien. Rio de Janeiro: Zahar, 2001.

BARDIN, L. Análise de Conteúdo. Lisboa: Edições 70, 2011.

BARROS, A. L. da S. Sequências explicativas produzidas pela criança de cinco anos de idade em atividade lúdica. 2006. 141 f. Dissertação (Mestrado em Semiótica e Linguística Geral) - Universidade de São Paulo, São Paulo.

BEZERRA, C. B. Distantes do berço: impactos psicológicos da imigração na infância. 2016. Dissertação (Mestrado em Psicologia) - Universidade Federal de Santa Catarina, Florianópolis, 2016. 158 p.

BORGES, V. Os refugiados da terra: uma problemática ético-política inspirada nas abordagens freireanas. Curitiba: CRV, 2019.

BRANT, D; MACHADO, R. Sob Bolsonaro, verba para missões de paz atinge mínima 
histórica. São Paulo, 19 de set. 2020. Disponível em: $<$ https://www1.folha.uol.com.br/mundo/2020/09/sob-bolsonaro-verba-para-missoesde-paz-atinge-minima-historica.shtml>. Acesso em: 09 mar. 2021.

CHARLES, V. Análise da identidade e da alteridade no sistema educacional haitiano. Dissertação (Mestrado em Educação). Faculdade de Educação, Universidade Estadual de Campinas. Campinas. 150 p. 2015.

GARCIA, R. R. Um olhar multidisciplinar sobre a realidade dos imigrantes haitianos em Santa Catarina. In: SEMINÁRIOS EM ADMINISTRAÇÃO DA UNIVALI, 21., 2018, Biguaçu. Anais eletrônicos ... Biguaçu: UNIVALI, 2018. p. 1-17. Disponível em: $<$ https://login.semead.com.br/21semead/anais/arquivos/1302.pdf $>$. Acesso em: 04 set. 2020.

FAETI, P. V. Representações de si, jogo e experiência: deslocamentos das identidades na formação docente. Orientador: Dra. Geiva Carolina Calsa. Tese (Doutorado em Educação) - Universidade Estadual de Maringá. Maringá, 2017. 153f.

FERREIRA, A. B. de H. Míni Aurélio: o dicionário de língua portuguesa. 8. ed. Curitiba: Positivo, 2010.

FREIRE, P.; ILLICH, I. Diálogo. In: Seminario Invitación A Concientizar y Desescolarizar: Conversación permamente, Genebra, 1974. Atas. Buenos Aires, Búsqueda Celadec. 1975, $109 \mathrm{p}$.

GARCIA, R. R. Um olhar multidisciplinar sobre a realidade dos imigrantes haitianos em Santa Catarina. In: Seminários em Administração da Univali, 21., 2018, Biguaçu. Anais eletrônicos... Biguaçu: Univali, 2018. p. 1-17. Disponível em: $<$ https://login.semead.com.br/21semead/anais/arquivos/1302.pdf $>$. Acesso em: 04 set. 2020.

GRAJZER, D. E. Crianças refugiadas: um olhar para infância e seus direitos. Orientadora: Luciane Maria Sclindwein. 2018. Dissertação (Mestrado) - Universidade Federal de Santa Catarina, Florianópolis, 2018. 138 p.

HEYWOOD, C. Uma história da infância: da Idade Média à época contemporânea no Ocidente. Tradução: Roberto Cataldo Costa. Porto Alegre: Artmed, 2004.

KOLTAI, C. A recepção nacional do estrangeiro no mundo globalizado. In: VIEIRA, Listz (org.). Identidade e globalização. Rio de Janeiro: Record, 2009.

LAJOLO, M. Infância de papel e tinta. In: FREITAS, Marcos Cezar de (org.). História Social da Infância no Brasil. São Paulo: Cortez, 1997. p. 312. 
MONTANHER, J. D. da S.

LOURO, G. L. Gênero, sexualidade e educação: Uma perspectiva pós- estruturalista. Petrópolis: Vozes, 1997.

MANTOVANI, F.; DIEGUES, L. 'Cidade imigrante', São Paulo recebe quase 57 mil bolivianos em 20 anos. Disponível em:

<https://www1.folha.uol.com.br/cotidiano/2020/01/cidade-imigrante-sao-paulorecebe-quase-57-mil-bolivianos-em-20-anos.shtml>. Acesso em: 24 mar. 2020.

MAISONNAVE, F. Manifestações violentas no Haiti pedem renúncia de presidente acusado de corrupção. Disponível em: $<$ https://fotografia.folha.uol.com.br/galerias/1648374312064754-manifestacoesviolentas-no-haiti-pedem-renuncia-de-presidente>. Acesso em: 11 nov. 2019.

MARTINS-BORGES, L. Migração involuntária como fator de risco à saúde mental. Revista Interdisciplinar da Mobilidade Humana, Brasília, v. 21, n. 40, p. 151-162, jan./jul. 2013.

MIYAHIRA, E; RODRIGUES, L. M. O; SOARES, C. de F. Imigração recente e educação, o caso do Estado de São Paulo e sua metrópole. São Paulo: ABEP, 2014. Disponível em: $<$ http://www.abep.org.br/ abeporgb/abep.info/files/trabalhos/trabalho_completo/TC1-5-765-677.pdf >. Acesso em: 21 out. 2020.

MIGRAR. In: MICHAELIS, Dicionário Brasileiro da Língua Portuguesa. Melhoramentos, 2020. Disponível em: <https://michaelis.uol.com.br/moderno\%20portugues/busca/portugues-brasileiro/migrar>. Acesso em: 25 ago. 2020.

MIGRANTE, IMIGRANTE, EMIGRANTE, REFUGIADO, ESTRANGEIRO: QUAL PALAVRA DEVO USAR? Migrações em Debate, 2019. Disponível em: < http://www.museudaimigracao.org.br/blog/migracoes-em-debate/migrante-imigranteemigrante-refugiado-estrangeiro-qual-palavra-devo-usar >. Acesso em: 25 ago. 2020.

RODRIGUES, M. L. O. et al. Imigração recente e educação, o caso do Estado de São Paulo e sua metrópole. São Paulo: ABEP, 2014. Disponível em: <http://www.abep.org.br/ abeporgb/abep.info/files/trabalhos/trabalho_completo/TC1-5- 765-677.pdf >. Acesso em: 21 out. 2020.

NETO, H. P. Migrações Internas e Mobilidade do trabalho no Brasil Atual. Experimental, São Paulo, n. 2, p. 11-24, mar. 1997.

PIMENTEL, A; ARAÚJO, L. da S. Concepção da criança na pósmodernidade. Revista Psicologia Ciência e Profissão, São Paulo, v. 2, n. 27, p. 184-193, jan./jun. 2007.

PROSPERE, R. Educação e transformação social no/do Haiti à luz (da pedagogia braçal) de Frantz Fanon. Campinas: Mercado de Letras, 2017.

SÃO BERNARDO, M. A. de. Português como língua de acolhimento: um estudo com imigrantes e pessoas em situação de refúgio no Brasil. 2016. Tese (Doutorado) - 
Um estudo de caso no município de Maringá-PR: ...

Universidade Federal de São Carlos, São Carlos, 2016. 206 p.

SILLER, R. R. Infância, Educação Infantil, Migrações. Tese (Doutorado em Educação) Universidade Estadual de Campinas. Campinas, 2011.

UNIÃO EUROPEIA. Resolução do Parlamento Europeu. Disponível em: <https://www.europarl.europa.eu/doceo/document/TA-8-2018-0036_PT.html $>$. Acesso em: 02 abr. 2021.

Juliane Daiane da Silva Montanher: Mestranda na Universidade Estadual de Maringá, Maringá, Paraná, Brasil.

Orcid: https://orcid.org/0000-0002-5840-9285

E-mail: juliane.daiane@smail.com

Este periódico utiliza a licença Creative Commons Attribution 3.0, para periódicos de acesso aberto (Open Archives Initiative - OAI). 